ment of the costochondral junctions and thickening of the wrists and ankles. X-ray shows cupping and widening of the distal ends of long bones. The serum alkaline phosphatase is raised and both calcium and phosphorus are diminished (Back \& Cole, 1958; Palmer \& Thomas, 1958).

Cretinism in which there is stunted growth, delay in closure of the fontanelle, large tongue and umbilical hernia. The serum cholesterol is raised and there is anaemia.

\section{Conditions with widely separated cranial sutures}

Osteogenesis imperfecta in which there is diminished radiological density of bones, subject to multiple fractures. The sclerae are sometimes blue. There are two varieties; one intra-uterine in which fractures are much more prone, and a post-natally occurring type, with a better prognosis. Blood chemistry is normal.

Cleidocranial dysostosis. In this the cranial sutures are widely separated and, in addition, the entire clavicle or its middle portion is absent.

Albers-Schonberg disease. The bones are brittle and easily fractured. Haemolytic anaemia occurs, and hepatosplenomegaly and lymph node enlargement owing to extramedullary haematopoiesis. Radiological picture: increased density of bone with obliteration of the bone marrow. In the skull the increased density is especially noted at the base. For further information see Fourman \& Royer (1968).

\section{Acknowledgments}

I wish to thank Dr Levy, Senior Radiologist, University of Witwatersrand, for his report on the X-rays and for making the diagnosis, Dr Glatthaar, Medical Adviser, AngloAmerican Corporation (Zambia), who originally diagnosed osteopetrosis and who sought the opinion of Dr Levy, Mr B. Stocks, United Church of Zambia, who kindly assisted by taking the photographs; finally, Dr V. G. Caiger, Chief Medical Officer, Bancroft Mines Hospital, for his encouragement and helpful criticisms and suggestions and for permission to publish.

\section{References}

BACK, E.H. \& Cole, W.R. (1958) Osteopetrosis associated with rickets and scurvy. Brit. J. Radiol. 31, 709.

Elmore, S.M. (1967) Pycnodysostosis: a review. J. Bone Jt Surg. 49A, 153.

Fourman, P. \& Royer, P. (1968) Calcium Metabolism and the Bone, 2nd edn. Blackwell Scientific Publications, Oxford and Edinburgh.

MaroteauX, P. \& LAMY. M. (1962) Deux observations d'une affection osseuse condensante: la pycnodysotose. Arch. franc. Ped. 19, 267.

MaroteauX, P. \& LAMY, M. (1965) The malady of ToulouseLautrec. J. Amer. med. Ass. 191, 715.

Palmer, P.E.S. \& Thomas, J.E.P. (1958) Osteopetrosis with unusual changes in the skull and digits. Brit. $J$. Radiol. 31, 705.

Schuler, S. (1963) Pycnodysostosis. Arch. Dis. Child. 38, 620.

\title{
Hypermobility of the superior tibio-fibular joints
}

\author{
T. G. J. BRIGHTMORE \\ F.R.C.S.
}

\section{Kingston Hospital, Surrey}

IN NORMAL persons joint mobility varies with age, body-build and race. Joint laxity decreases with age and is often increased in thin individuals, African Negroes, Indians and Pakistanis (Kirk, Ansell \& Bywaters, 1967). Unduly lax joints with a greater range of movement than the accepted normal are termed hypermobile, and this may be temporary or persistent. The former, occurring in the pregnant woman, is due to a uterine hormone causing increased maternal joint laxity (Hisaw, 1926; Wilkinson, 1963), and which, after passing into the foetal circulation (Chapple \& Davidson, 1941) also causes foetal and transient neonatal joint laxity because of its inadequate conjugation by an immature foetal liver (Andrén \& Borglin, 1961). Persistent hypermobility may be congenital or acquired. The acquired type may be compensatory to a contiguous rigid joint, or follow muscle disease, neuropathic joint disease, trauma or inflammatory polyarthritis. Congenital hypermobility has been observed in certain mesenchyme dysplasias producing disproportion in bone and ligament growth rates. These include achondroplasia (Sutro, 1947), osteogenesis imperfecta (Key, 1927), Marfan's syndrome, the Ehlers-Danlos syndrome (McKusick, 1966) and the Achard syndrome (Parish, 1960). It has been noted in the rare metabolic conditions of homocystinuria (Schimke et al., 1965) and hyperlysinaemia (Ghadimi, Binnington \& Pecora, 1965). It is also seen in congenital dislocation of the hip (Lorenz, 1920; Carter \& Wilkinson, 1964) and recurrent dislocation of patella and shoulder (Sutro, 1947; Carter \& Sweetnam, 1960).

Hypermobility also occurs in otherwise normal people, often with a familial incidence (Finkelstein, 1916; Key, 1927; Sutro, 1947; Carter \& Sweetnam, 


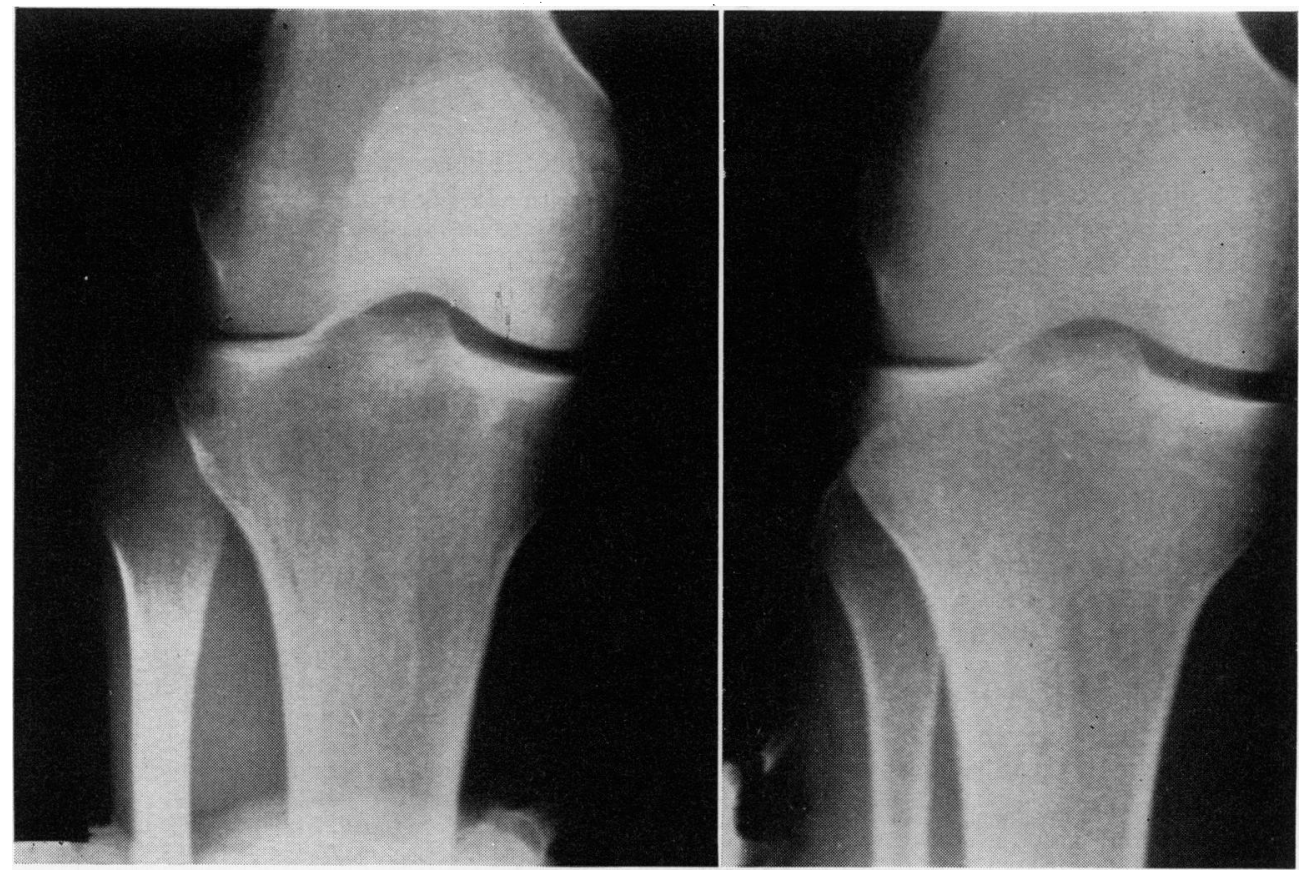

Fig. 1. Antero-posterior radiographs of right joint at rest (left) and with pressure (right).

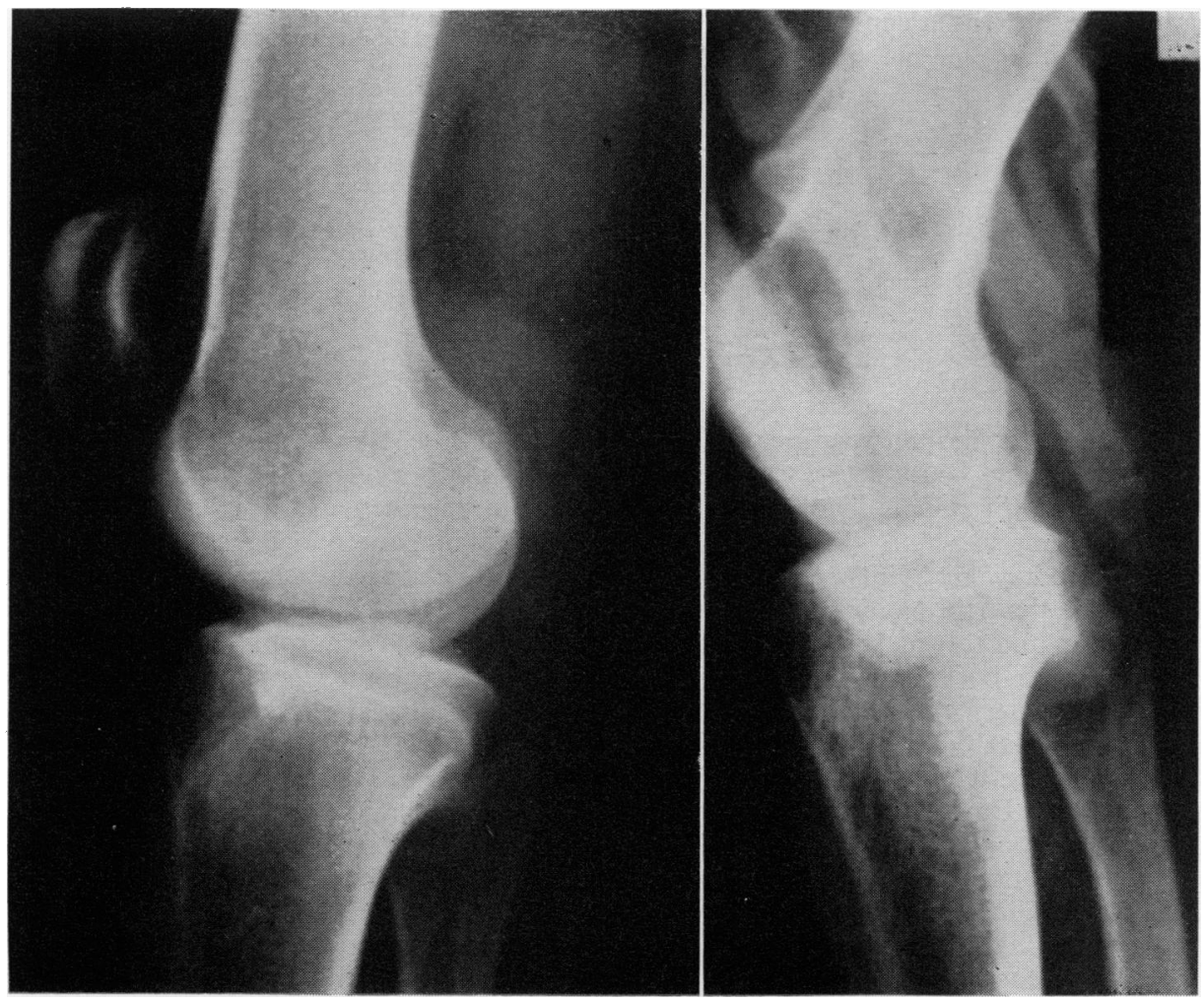

Fig. 2. Lateral radiographs of right joint at rest (left) and with pressure (right). 


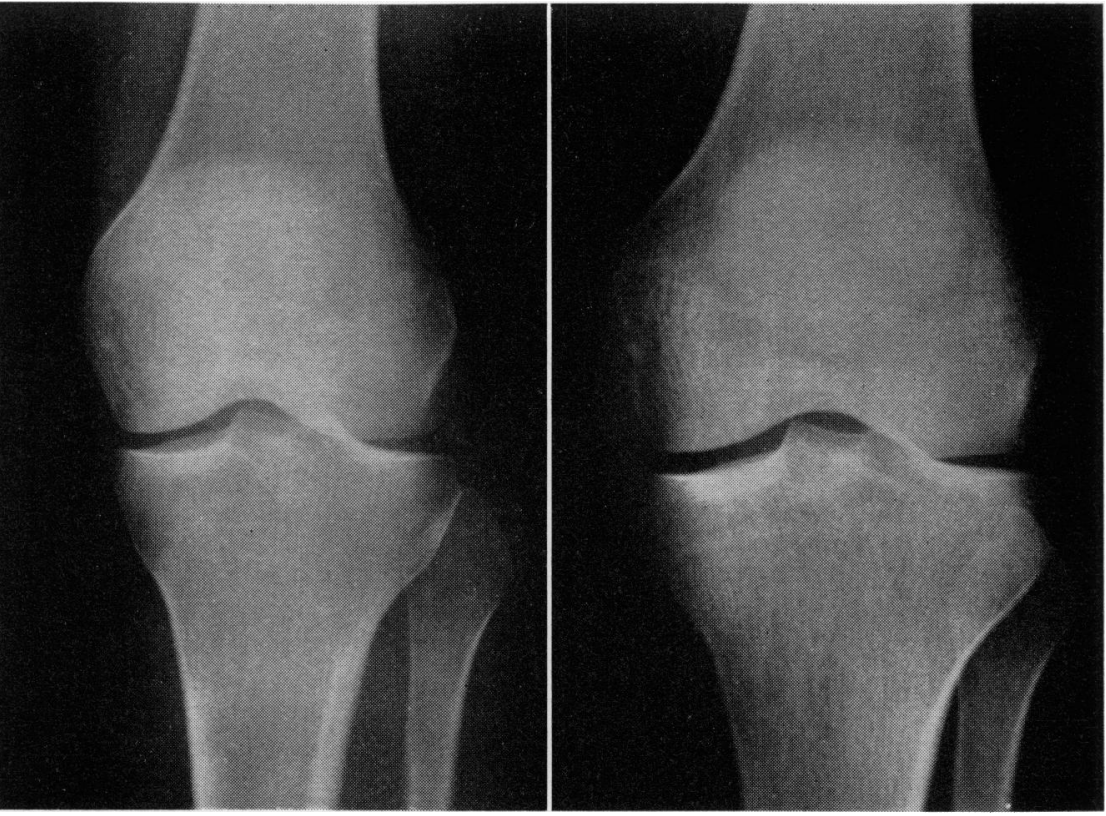

FIG. 3. Antero-posterior radiograph of left joint at rest (left) and with pressure (right).

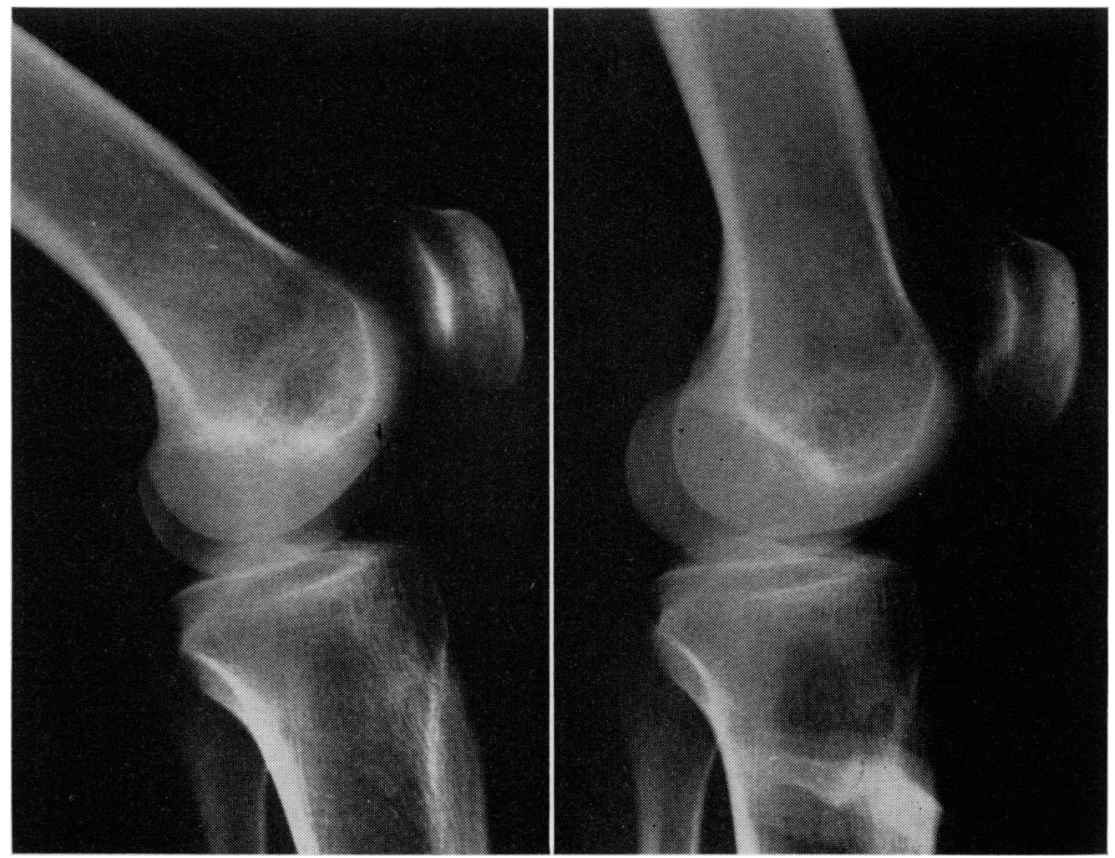

Fig. 4. Lateral radiographs of left joint at rest (left) and with pressure (right). 
1958). Complete involvement of all joints is rare (Hass \& Hass, 1958). Carter \& Wilkinson (1964) noted laxity of four or more pairs of joints in $7 \%$ of a schoolchildren sample and Sutro (1947) found that $4 \%$ of an adult orthopaedic outpatient sample possessed hypermobility of three or more pairs of joints. Isolated hypermobility of certain joints, notably fingers and thumbs, is not uncommon (Sturkie, 1941). A search of the literature failed to reveal a case of isolated bilateral hypermobility of the superior tibio-fibular joints without dislocation in one or the other, and for this reason the following case is reported.

\section{Case report}

Miss H.H., a 21-year-old Caucasian typist, was admitted in December 1967 following a road traffic accident in which she was concussed and received minor injuries. There was no clinical or radiological evidence of bone or joint injury, but both fibula heads exhibited an abnormal degree of painless mobility. This was confirmed radiologically with rest and stress films when the fibula heads could be subluxed about it in. posteriorly (see Figs. 1-4). Both ankles were hormal clinically and radiologically. No other joint was hypermobile and the patient was unaware of this symptomless hypermobility. Apart from a height of $4 \mathrm{ft} 9 \frac{3}{4} \mathrm{in}$. and a weight of $87.5 \mathrm{lb}$ she was normal for her age and there was no history or evidence of the above-mentioned diseases. She could not recollect a familial history of joint laxity and attemyts at investigating members of her family were unsuccessful.

\section{Discussion}

The superior tibio-fibular joint is a synovial joint, the cavity of which may communicate posteriorly with the popliteus bursa and thence with the kneejoint. The fibula head, which varies in size, shape and position,' carries on its upper surface, an oval or round articular facet facing forwards and upwards, the obliquity of which varies with the position of the head and the degree of convexity of the lateral aspect of the talus. This facet is absent in cases in which the head is so low that it fails to articulate with the reciprocal facet on the postero-lateral aspect of the upper tibial epiphysis (Shanks \& Kerley, 1959). The stability of the joint is dependent on support from the arcuate ligament, short external lateral ligament of the knee-joint, and the fibular collateral ligament together with the interosseous membrane and the interosseous ligaments at the lower end of the fibula. The ilio-tibial tract and biceps tendon are inserted into the head of the fibula, the former through the fibular collateral ligament. Their function is probably to stabilize the fibular component of the leg in weight bearing, and to exert some control on the passive movements of the superior tibio-fibular joint (Helfet, 1963), the amount of which is related to the variable shape of the talus (Barnett \& Napier, 1962). The upper and medial surfaces of the talus are in contact with the tibia in all positions of the ankle joint, but in order for the lateral malleolus to maintain contact with the lateral facet of the talus, rotary and lateral movements occur at the lower end of the fibula with reciprocal movements at the superior tibio-fibular joint. The lateral facet of the talus is usually concave from above downwards and convex anteroposteriorly. Normally the superior tibio-fibular joint surfaces are nearly horizontal to allow rotation, but if the lateral surface of the talus is plane then the surfaces are nearly vertical to facilitate gliding.

Hypermobile joints may be symptomless. They may be accompanied by muscle pains and are liable to be injured by minor degrees of trauma with the development of synovitis, effusion and degenerative arthritis. The hypermobility syndrome consists of these musculo-skeletal complaints associated with generalized joint hypermobility, the treatment of which is reassurance and the avoidance of traumatic activities (Kirk et al., 1967). Instability and even osteo-arthritis of the superior tibio-fibular joint do not always incapacitate the patient, and perhaps because of this, the joint has not received sufficient clinical and literary attention (Helfet, 1963). The head of the fibula has been termed a poor relation of the knee-joint (Harrison \& Hindenach, 1959). Hypermobility of the superior tibio-fibular joint may cause discomfort in the ankle on walking, discomfort and tenderness in the region of the joint from strain of the biceps tendon and may even simulate deep vein thrombosis (Helfet, 1963). Because of its protected position and strong ligamentous support, dislocation of the joint first described by Nélaton (1874) is uncommon and is usually post-traumatic (Lyle, 1925; Lord \& Coutts, 1944; Pillmore, 1947; Vitt, 1948). Harrison \& Hindenach (1959) thought that dislocation was frequently undiagnosed and, therefore, more common than the literature suggested. These authors emphasized that the joint should always be examined following injury to the ankle or tibia, and it is important to differentiate symptoms of hypermobility and dislocation from those of lateral meniscus damage (Helfet, 1963). Dislocation may also occur in amputation stumps and in local growth disturbances such as osteo-myelitis. Dennis \& Rutledge (1958), Harrison \& Hindenach (1959) and Owen (1968) have reported dislocation in congenitally lax joints. Key (1927) did not observe a greater susceptibility to dislocation in generalized joint laxity. Closed reduction which is usually easy and satisfactory is effected by strongly inverting the 
foot, flexing the knee (to relax the biceps) and applying pressure. Open reduction is occasionally required, especially in the less common posterior dislocation when the common peroneal nerve may be damaged, as it was in the case reported by Dennis \& Rutledge (1958).

\section{Acknowledgments}

I wish to thank Mr W. J. D. Bradfield for allowing me to report this case; Dr S. Holesh for her help with the radiographs, and Mr A. Graham Apley for his helpful comments.

\section{References}

ANDRÉN, L. \& Borglin, N.E. (1961) Disturbed urinary excretion pattern in newborns with congenital dislocation of the hip. Acta endocr. (Kbh.), 3, 423; 427.

BARNETT, C.H. \& NAPIER, J.R. (1952) The axis of rotation at the ankle joint in man. Its influence upon the form of the talus and the mobility of the fibula. J. Anat. 86, 1 .

Carter, C. \& Sweetnam, R.L. (1958) Familial joint laxity and recurrent dislocation of the patella. $J$. Bone $J t$ Surg. 40B, 664.

CARTER, C. \& Sweetnam, R.L. (1960) Recurrent dislocation of the patella and of the shoulder. J. Bone Jt Surg. 42B, 721.

Carter, C. \& Wilkinson, J. (1964) Persistent joint laxity and congenital dislocation of the hip. J. Bone Jt Surg. 46B, 40.

Chapple, C.C. \& Davidson, D.T. (1941) A study of the relationship between fetal position and certain congenital deformities. J. Pediat. 18, 483.

DenNis, J.B. \& RutLedge, B.A. (1958) Bilateral recurrent dislocations of the superior tibio-fibular joint with peroneal nerve palsy. J. Bone Jt Surg. 49A, 1146.

FinKelstein, H. (1916) Joint hypotonia. N.Y. med. J. 104, 942.

Ghadimi, H., Binnington, V.I. \& Pecora, P. (1965) Hyperlysinaemia associated with retardation. New Engl. J. Med. 273, 723.

HARRISON, R. \& HiNdENACH, J.C.R. (1959) Dislocation of the upper end of the fibula. J. Bone Jt Surg. 41B, 114.

Hass, J. \& Hass, R. (1958) Arthrochalasis multiplex congenita. J Bone Jt. Surg. 49A, 663.
Helfet, A.J. (1963) The Management of Internal Derangements of the Knee. Pitman, London.

Hisaw, F.L. (1926) Experimental relaxation of the pubic ligamanets in the guinea pig. Proc. Soc. exp.Biol. (N.Y.), 23, 661 .

KEY, J.A. (1927) Hypermobility of joints as a sex linked hereditary characteristic. J. Amer. med. Ass. 88, 1710.

Kirk, J.A., Ansell, B.M. \& Bywaters, E.G.L. (1967) The hypermobility syndrome: musculoskeletal complaints associated with generalised joint hypermobility. Ann. Rheum. Dis. 26, 419.

LORD, C D. \& CoutTs, J.W. (1944) A study of typical parachute injuries occurring in two hundred and fifty thousand jumps at the parachute school. J. Bone $J t$ Surg. 26, 551.

Lorenz, A. (1920) Die Sogenannte Angeborenen Hüftuerrenkung ihre Pathologie und Therapie. Deutsche Orthopadie (Ed. by H. Gocht), Band 3. F. Enke, Stuttgart.

LYLE, H.H.M. (1925) Traumatic luxation of the head of the fibula. Ann. Surg. 82, 635 .

McKusick, V.A. (1966) Heritable Disorders of Connective Tissue, 3rd edn. C. V. Mosby, St Louis.

Nélaton, A. (1874) Éleménts de Pathologie Chirurgicale, 2nd edn, Vol. 3, p. 282. Librairie Germer Balliére, Paris.

OwEN, R. (1968) Recurrent dislocation of the superior tibio-fibular joint-a diagnostic pitfall in knee joint derangement. J. Bone Jt Surg. 50B, 342.

PARISH, J.C. (1960) Skeletal syndromes associated with arachnodactyly. Proc. roy. Soc. Med. 53, 515.

Pillmore, G.U. (1947) Clinical Radiology, Vol. II, p. 300. Davis, Philadelphia.

Schimke, R.H., McKusick, V.A., Huang, T. \& Pollak,

A.D.J. (1965) Homocystinuria: study of 20 families with 38 affected members. J. Amer. med. Ass. 193, 711.

Shanks, S.C. \& Kerley, P (1959) Text Book of X-ray Diagnosis, 3rd edn, p. 34. H. K. Lewis, London.

Sturkie, P.D. (1941) Hypermobile joints in all descendants for two generations. J. Hered. 32, 232.

SuTro, C.J. (1947) Hypermobility of bones due to 'overlengthened' capsular and ligamentous tissues; a cause for intra-articular effusions. Surgery, 21, 67.

VITT, R.J. (1948) Dislocation of the head of the fibula. $J$. Bone Jt Surg. 30A, 1012.

Wilkinson, J.A. (1963) Prime factors in the etiology of congenital dislocation of the hip. J. Bone Jt Surg. 45B, 268.

\title{
The myocardium in periodic paralysis
}

\author{
N. K. CONI \\ M.R.C.P., F.R.C.P.(C.) \\ Major, R.A.M.C., \\ British Military Hospital, \\ Singapore
}

A CASE of familial periodic paralysis is reported in order to present the electrocardiographic changes observed during a series of artificially precipitated attacks. These changes draw attention to the present ignorance of the metabolic disturbances underlying this disorder and of the precise significance of the hypokalaemic electrocardiogram.

\section{Case report}

A 23-year-old Malay soldier was admitted to 